Proceedings

\title{
E-tongue based on Porphyrin Electropolymers for Apulian Red Wines Defects Detection +
}

\author{
Larisa Lvova ${ }^{1, *}$, Corrado Di Natale ${ }^{2}$ and Roberto Paolesse ${ }^{1}$ \\ 1 Department of Chemical Sciences and Technology, University "Tor Vergata”, 00133 Rome, Italy; \\ roberto.paolesse@uniroma2.it \\ 2 Department of Electronic Engineering, University “Tor Vergata”, 00179 Rome, Italy; \\ dinatale@eln.uniroma2.it \\ * Correspondence: larisa.lvova@uniroma2.it; Tel.: +39-06-7259-4755 \\ + Presented at the Eurosensors 2017 Conference, Paris, France, 3-6 September 2017.
}

Published: 8 August 2017

\begin{abstract}
An application of e-tongue based on porphyrin electropolymers for the detection of Primitivo and Negroamaro wines defects related to the presence of "off-odor" methiol (3(methylthio)-propanol), isoamyl alcohol fusel oil, the marker of the yeast activity benzaldehyde and vinegar formation marker acetic acid was investigated. The best results were obtained for acetic acid and isoamyl alcohol. Further the Soft Independent Modelling by Class Analogy, SIMCA, classification models and Partial Least Squares-Discriminant Analysis, PLS-DA, were employed to distinguish real wine samples with different (permitted and alarm levels) fault compounds content as far as two types of wines among them.
\end{abstract}

Keywords: e-tongue; porphyrin electropolymers; wine faults detection

\section{Introduction}

The well recognizable wine taste is essential in order maintain the brand uniformity, [1]. Despite wine contains hundreds of different substances, the minor concentration variation of even one taste responsible component may change or damage the overall wine aroma perception, and hence the detection of possible wine defects is an important issue [2].

In the present study we continue our researches [3] on the quality assessment of 24 samples of Apulian wines produced by different cantinas and made of $100 \%$ Primitivo (10 wines) or Negroamaro (14 wines) grape varieties was performed by means of e-tongue system based on 8 porphyrin electropolymers obtained by electrodeposition of n-alkyl-(1-pyrrole) phenyl-substituted porphyrins and aminophenyl substituted porphyrin polymeric coatings on Pt WE/Table 1. The properties of utilized porphyrin electropolymer sensing films were studied in details recently $[4,5]$.

Table 1. Composition and electropolymerization conditions of $E$-tongue sensors.

\begin{tabular}{cccc}
\hline \multirow{2}{*}{ Sensor } & \multirow{2}{*}{ Monomer } & \multicolumn{2}{c}{ Film Electropolymerisation Conditions } \\
\cline { 2 - 4 } & & Potential Range, $\mathbf{V}^{* *}$ & Solvent \\
\hline 1 & CoTrisAminoTPP & -0.3 to 1.3 & $\mathrm{CH}_{2} \mathrm{Cl}_{2}+2 \% \mathrm{ACN}$ \\
2 & FeClMonoAminoTPP & -0.5 to 1.4 & $\mathrm{CH}_{2} \mathrm{Cl}_{2}$ \\
3 & MnClMono-AminoTPP & -0.5 to 1.5 & $\mathrm{CH}_{2} \mathrm{Cl}_{2}$ \\
4 & CuTrisAminoTPP & -0.5 to 1.5 & $\mathrm{CH}_{2} \mathrm{Cl}_{2}$ \\
5 & CoTPP-Mono-O-(CH $\left.\mathrm{CH}_{2}\right)$-pyrr & -0.5 to 1.5 & $\mathrm{CH}_{2} \mathrm{Cl}_{2}$ \\
6 & MnClTPP-Mono-O-(CH$\left.)_{2}\right)$ 10-pyrr & -0.3 to 1.3 & $\mathrm{CH}_{2} \mathrm{Cl}_{2}$ \\
7 & bis-pyrrPorf & -0.3 to 1.4 & $\mathrm{CH}_{2} \mathrm{Cl}_{2}$ \\
8 & Mono-O-( $\left(\mathrm{CH}_{2}\right)$ 10-pyrrPorf & -0.3 to 1.4 & $\mathrm{CH}_{2} \mathrm{Cl}_{2}$ \\
\hline
\end{tabular}

* monomer concentration in all solutions was $1 \mathrm{mM}$, the background electrolyte TBAClO4concentration was $0.1 \mathrm{M}$; ${ }^{* *} 20$ cycles, $100 \mathrm{mV} / \mathrm{s}$ potential scanning rate. 


\section{Results and Discussion}

First E-tongue array was calibrated in 16 artificial wine solutions containing the threshold or elevated content of compounds responsible for the wine organoleptic faults: methiol (3-(methylthio)propanol), isoamyl alcohol, benzaldehyde and acetic acid, Table 2.

Table 2. The amounts of wine defect compounds in artificial wine calibration solutions and in Negroamaro wine and artificial wine composition *.

\begin{tabular}{lllll}
\hline & \multicolumn{3}{c}{ Content, $\mathbf{m g} / \mathbf{L}$} \\
\hline & $\begin{array}{l}\text { Permitted } \\
\text { Amount }\end{array}$ & Alarm & Defect & $\begin{array}{l}\text { Added to } \\
\text { Negroamaro }\end{array}$ \\
\hline Benzaldehyde & 0.015 & 3 & 6 & $3-1000$ \\
\hline Acetic acid & 750 & 1000 & 2000 & $1000-100,000$ \\
\hline Isoamyl alcohol & 30 & 300 & 600 & $300-10,000$ \\
\hline Methiol & 1 & 2 & 4 & $1-100$ \\
\hline
\end{tabular}

* artificial wine: $5 \mathrm{~g} / \mathrm{L}$ tartaric acid, $123 \mathrm{~g} / \mathrm{L}$ ethanol, $0.3 \mathrm{~g} / \mathrm{L}$ isobutyl alcohol, $0.06 \mathrm{~g} / \mathrm{L}$ isoamyl alcohol, $\mathrm{pH}=3.2$.

As previously reported in [3], obtained PLS1 regression modes showed a good correlation between the amount of defect compounds and e-tongue response with the correlation coefficients of 0.925, 0.852 and 0.821 for benzaldehyde, isoamyl alcohol and acetic acid respectively. These results were indicating a possibility of pyrrol-substituted- and aminophenyl-porphyrins employment as sensing materials to detect the wine adulterations in artificial matrix of close to the wine composition.
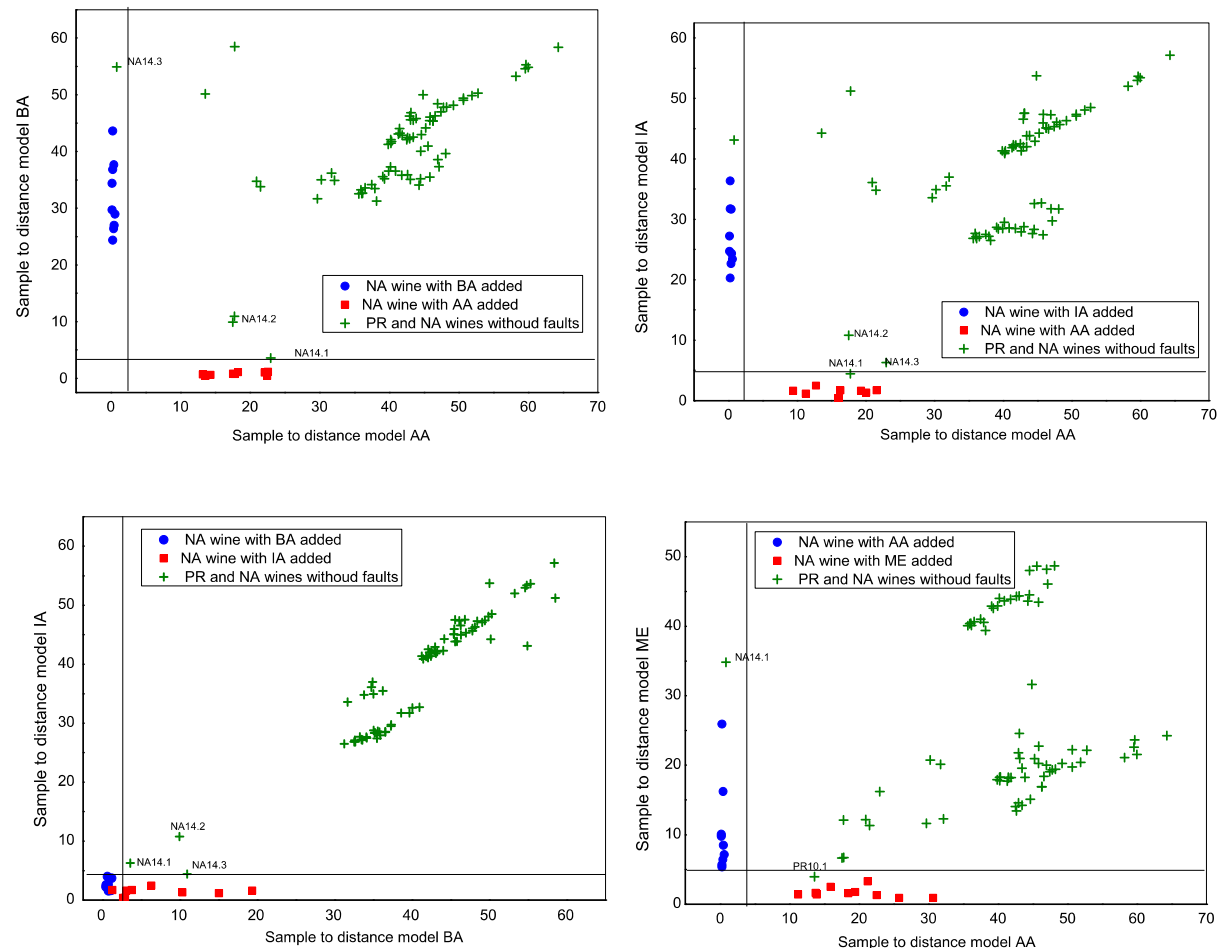

Figure 1. Coomans plot of Apulian wines (green points) SIMCA classification in respect to benzalhehyde (BA), isoamyl alcohol (IA), acetic acid (AA) and methiol (ME) defects presence.

Further the analysis of real wine samples was done in order to identify the possible presence of defect compounds in the threshold, alarm and/or defect amounts. The adequate predictive power of e-tongue in Negroamaro wine samples was found for isoamyl alcohol and acetic acid, $R^{2} c a l=0.994$ $\left(R^{2} \mathrm{val}=0.732\right)$ and $\mathrm{R}^{2} \mathrm{cal}=0.999\left(\mathrm{R}^{2} \mathrm{val}=0.989\right)$ correspondingly, while the lower correlation coefficients were received for other wine fault compounds.

We have then focused on Primitivo and Negroamaro wines classification in relation to four fault compounds tested in two-component SIMCA models. Negroamaro wine samples with added fault 
compounds in three different concentrations (corresponding to permitted amount, alarm and defect content, see Table 2) were used to create the models along the Coomans plot axis shown in Figure 1. Almost all Apulian wines were all classified as non-containing fault compounds in in concentrations higher than the maximum permitted amount.

The one-leave-out PLS-DA cross-validation was conducted on two data sets, one composed of 14 Negroamaro and 10 Primitivo wines and another formed from 29 Negroamaro wine samples (15 samples with added fault compounds and 14 authentic wines). Tree Negroamaro and four Primitivo wines were misclassified, thus resulting in correct discrimination of $71 \%$ of two authentic monocultivar Apulian wines. In a case of discrimination between Negroamaro wines with and without added fault compounds, only one wine sample was misclassified and the correct classification of $97 \%$ of samples was obtained, thus demonstrating the utility of porphyrin electropolymers-based e-tongue for red wines defects detection.

Conflicts of Interest: The authors declare no conflict of interest.

\section{References}

1. Jackson, R.S. Wine Science, Principles, Practice, Perception, 2nd ed.; Academic Press: Waltham, MA, USA, 2000.

2. Guanais Branchini, C.; Lvova, L.; Di Natale, C.; Paolesse, R. Wine and combined electronic nose and tongue. In Electronic Nose and Tongue in Food Science; Rodriguez-Mendez, M.L., Ed.; Academic Press: Waltham, MA, USA, 2016; pp. 291-300.

3. Lvova, L.; di Natale, C.; Paolesse, R. Electronic tongue based on porphyrins for Apulian red wines defects detection, DOI: 10.1109/ISOEN.2017.7968917, In Proc. ISOCS/IEEE International Symposium on Olfaction and Electronic Nose (ISOEN).

4. Lvova, L.; di Natale, C.; Lundström, I.; Paolesse, R. Towards hyphenated sensors development: Design and application of porphyrin electropolymer materials. Electroanalysis 2012, 24, 776-789.

5. Lvova, L.; Paolesse, R.; di Natale, C.; D'Amico, A.; Bergamini, A. Development of potentiometric polymeric film sensors based on $\mathrm{Co}(\mathrm{II})$ - and $\mathrm{Cu}(\mathrm{II})$-porphyrinates for analysis of biological fluids. Int. J. Electrochem. 2011, doi:10.4061/2011/930203.

(C) 2017 by the authors. Licensee MDPI, Basel, Switzerland. This article is an open access article distributed under the terms and conditions of the Creative Commons Attribution (CC BY) license (http://creativecommons.org/licenses/by/4.0/). 